\title{
OPEN Rice husk derived Aminated Silica for the efficient adsorption of different gases
}

\author{
Rashed S. Bakdash ${ }^{1}$, Isam. H. Aljundi ${ }^{\bowtie}{ }^{\bowtie}$ Chanbasha Basheer $^{1 \bowtie}$ \& Ismail Abdulazeez ${ }^{1}$
}

In this present work, we successfully prepared aminated silica $\left(\mathrm{ASiO}_{2}\right)$ from rice husk ash (RHA) and functionalized with 3-aminopropyltriethoxysilane (APTES). Physical and chemical properties of the synthesized material were investigated by various techniques SEM-EDX, XPS, FTIR, TGA. The surface area of RHA was $223 \mathrm{~m}^{2} / \mathrm{g}$, while for $\mathrm{ASiO}_{2}$ was $101 \mathrm{~m}^{2} / \mathrm{g}$. Molecular level DFT calculations revealed that the functionalization of $\mathrm{ASiO}_{2}$ resulted in a significant decrease in the HOMO-LUMO energy gap, a reduction in hardness, and a consequent increase in charge transfer characteristics. The adsorption behavior at low pressure ( $1 \mathrm{~atm}$.) of aminated silica on different gases $\mathrm{CO}_{2 \prime} \mathrm{CH}_{4 \prime} \mathrm{H}_{2}$, and $\mathrm{N}_{2}$ at temperatures 77, 273, $298 \mathrm{~K}$ was studied. The adsorption of hydrogen was reported for the first time on aminated silica with an excellent adsorption capacity of $1.2 \mathrm{mmol} / \mathrm{g}$. The $\mathrm{ASiO}_{2}$ exhibited excellent performance in terms of gas separation in binary mixtures of $\mathrm{CO}_{2} / \mathrm{CH}_{4}, \mathrm{CO}_{2} / \mathrm{N}_{2}$ and $\mathrm{CO}_{2} / \mathrm{H}_{2}$ at 273 , and $298 \mathrm{~K}$, respectively. The catalyst further exhibits high stability during three cycles with less than $10 \%$ variation in the separation capacity.

The flexibility of silica-based mesoporous materials enables their functionalization with other materials, such as metal nanoparticles, or rare-earth elements ${ }^{1}$. Mesoporous silica has an advantage of high surface area and pore volume, high stability, unique pore structure characteristics, and uniform pore size distributions. It has been widely used in wastewater treatment, air purification, thermal insulation systems, oxygen, and humidity sensors and battery electrodes applications ${ }^{2}$. Other applications include as gas adsorbent due to its controllable pore size and volume. The functional groups present on the surface of mesoporous silica contributes significantly to its gas adsorption-desorption capacity and its interactions with other materials ${ }^{1,3}$.

The rising average temperature of the earth as a result of an increased presence of greenhouse gases such as $\mathrm{CO} 2$ have raised a lot of concerns in recent years. $\mathrm{CO}_{2}$ is considered one of the major contributors (up to $60 \%$ ) to total greenhouse gas emissions. To reduce the impact of $\mathrm{CO}_{2}$ gas, the $\mathrm{CO}_{2}$ Capture, Storage and Utilization technologies were introduced. However, the sustainability of these technologies remain of concern due to the cost implications ${ }^{4}$. The captured $\mathrm{CO} 2$ can be converted into valuable chemicals such as methane which is considered a green source of power generation in households ${ }^{4,5}$. The purification and upgrade of biogas $\left(\mathrm{CH}_{4}, \mathrm{CO}_{2}\right.$, and $\mathrm{N}_{2}$ ) to meet pure natural gas $\left(\mathrm{CH}_{4}\right)$ (pipeline quality) to avoid the corrosion can be achieved by effective cheap techniques to separate $\mathrm{CO}_{2}$ and $\mathrm{N}_{2}$ gas, such as absorption ${ }^{6}$, cryogenic separation ${ }^{7}$, membrane separation ${ }^{8}$, distillation ${ }^{9}$ and adsorption ${ }^{10}$. More specifically, solid adsorbents are more effective and less expensive than liquid absorbents like amine solvents, which have some restrictions due to their volatility, tendency to cause corrosion and high-energy consumption, especially in long-term application ${ }^{4,5,11-14} \cdot \mathrm{CO}_{2}$ capture as a physisorption process can be achieved by using activated carbon, silica gel, molecularly imprinted adsorbents, metal-organic frameworks (MOFs), and mesoporous molecular sieve ${ }^{2}$. The development of mesoporous materials have attracted more attentions in recent years for $\mathrm{CO}_{2}$ adsorption due to their high porosity, high gas diffusibility, and large pore volumes. Moreover, the separation capacity and selectivity of $\mathrm{CO}_{2}$ on mesoporous materials are not good enough. So, the improvement of these materials is highly attractive ${ }^{15}$. The functionalization of mesoporous adsorbent with various type of amines will enhance the interactions with $\mathrm{CO}_{2}$ compared with microporous materials due to the formation of ammonium carbamates and carbonates reversibly at moderate temperature ${ }^{16,17}$. Amine functionalization results in highly efficient $\mathrm{CO}_{2}$ capture at low temperature due to the strong interaction between the $\mathrm{CO}_{2}$ molecules and the porous structure, resulting in high gas diffusion through the adsorbent ${ }^{18}$.

Kumar et al. ${ }^{19}$, reported the functionalization of commercial silica with polyethyleneimine and 3-aminopropyltriethoxysilane (APTES) for $\mathrm{CO}_{2}$ capture. The amine functional group drastically enhanced the adsorption

${ }^{1}$ Department of Chemistry, King Fahd University of Petroleum and Minerals, Dhahran 31261, Saudi Arabia. ${ }^{2}$ Department of Chemical Engineering, King Fahd University of Petroleum and Minerals, Dhahran 31261, Saudi Arabia. ${ }^{\square}$ email: aljundi@kfupm.edu.sa; cbasheer@kfupm.edu.sa 
capacity of $\mathrm{CO}_{2}$, and the results revealed that the presence of higher amine contents resulted in higher $\mathrm{CO}_{2}$ uptake by the adsorbent. Similarly, rice husk derived mesoporous silica functionalized with various amines have been investigated for $\mathrm{CO} 2$ adsorption at different temperatures. The results showed that the branched amines exhibits higher $\mathrm{CO} 2$ adsorption capacities compared to straight-chain amines ${ }^{20,21}$. Zeng and Bai have reported a low-cost mesoporous silica with large pore volume impregnated with tetraethylenepentamine for efficient $\mathrm{CO}_{2}$ adsorption with a maximum $\mathrm{CO}_{2}$ uptake up to $173 \mathrm{mg} / \mathrm{g}^{22}$.

Recently, hydrogen adsorption on mesoporous silica SBA-15 was reported ${ }^{23}$. SBA-15 with a high surface area up to $3274 \mathrm{~m}^{2} / \mathrm{g}$ interestingly exhibited a low sorption capacity towards hydrogen at $77 \mathrm{~K}$ and $298 \mathrm{~K}^{24}$. To further improve the performance, mesoporous silica was functionalised with aluminium and platinum ${ }^{25}$ and titanium nanoparticles ${ }^{26}$. The presence of nanoparticles enhances the hydrogen uptake by two-folds. As the size of the nanoparticles decreases, the adsorption capacity increases. However, not many studies have reported the adsorption and separation of binary gases mixtures other than hydrogen.

In this study, rice husk-derived aminated silica $\left(\mathrm{ASiO}_{2}\right)$ was prepared and investigated for the adsorption and separation of a mixture of gases $\left(\mathrm{CO}_{2}, \mathrm{CH}_{4}, \mathrm{H}_{2}\right.$, and $\left.\mathrm{N}_{2}\right)$ at low-pressure (1 atm.) and varying temperatures (298, 273 and $77 \mathrm{~K})$.

Rice husk ash, RHA was extracted from rice husk and used to prepare the amine-modified silica ${ }^{2}$. The modification of RHA was conducted using APTES and confirmed by XRD, BET, FTIR, TGA, and SEM. The modified silica was used to study the adsorption of $\mathrm{CO}_{2}$. Molecular level DFT simulations were conducted to understand the underlying mechanistic insights into the role played by amine functional groups in the enhancement of the adsorption capacity of mesoporous silica. The present study demonstrates the role of amine presence in the enhancement of the adsorption and gas separation capacity of mesoporous silica materials, and would open up new horizons in the development of highly effective sorbents for CO2 capture.

\section{Experimental}

Chemicals and materials. Rice husk obtained from a rice mill from India and gained as a by-product of rice was employed as the initiating material without any pretreatment. Sulfuric acid $\left(\mathrm{H}_{2} \mathrm{SO}_{4}, 95 \%\right)$ was purchased from Cromoline for washing and cleaning of RH. RHA $\left(\mathrm{SiO}_{2}\right)$ was extracted from $\mathrm{RH}$ by heat treatment. Hydrochloric acid (37\%) for acidification of RHA and anhydrous toluene (99.8\%) as a solvent was bought from Sigma-Aldrich (St. Louis, USA). 3-aminopropyltriethoxysilane (APTES) was purchased from Sigma-Aldrich (St. Louis, USA).

Preparation of rice husk ash (RHA). The rice husk was washed with double distilled water (DDW) and $1.0 \mathrm{M}$ sulfuric acid to remove all impurities, then dried in the oven overnight at $100{ }^{\circ} \mathrm{C}$. Thereafter, the dried clean $\mathrm{RH}$ was ashed in the furnace at $700{ }^{\circ} \mathrm{C}$ for $6 \mathrm{~h}$.

Preparation of aminated silica $\left(\mathrm{ASiO}_{2}\right)$. $\mathrm{RHA}$ was soaked with $1.0 \mathrm{M} \mathrm{HCl}$ for $2 \mathrm{~h}$, then washed with double distilled water, then dried in the oven at $100{ }^{\circ} \mathrm{C}$ overnight. $5 \mathrm{~g}$ of the acidified silica was added in $50 \mathrm{~mL}$ of dry toluene with $5 \mathrm{~mL}$ of APTES while stirring for $24 \mathrm{~h}$ at $120^{\circ} \mathrm{C}$. The resultant product was washed with DDW and dried overnight in the oven at $100{ }^{\circ} \mathrm{C}^{27}$. The prepared aminated silica was called $\left(\mathrm{ASiO}_{2}\right)$.

Material characterization. Surface morphology. Scanning electron microscopy (SEM) (Lyra3 TESCAN) was performed to investigate the surface of the RHA and $\mathrm{ASiO}_{2}$ materials. Energy-dispersive X-ray spectroscopy (EDX) scan was conducted to examine the existence of the functional groups on the surface of prepared materials. X-ray photoelectron spectroscopy (VG Scientific ESCALAB Mk (II) spectrometer using a non-monochromatic $\mathrm{Al}$ source $(\mathrm{Ka}, 1486.6 \mathrm{eV})$ was used to confirm the elemental composition on the sorbent surface.

BET surface area. For the Brunauer-Emmett-Teller (BET) surface area measurements, $0.1 \mathrm{~g}$ of the sample was loaded in a BET quartz tube at $200{ }^{\circ} \mathrm{C}$ for two hours in a vacuum. Nitrogen adsorption isotherms were obtained by Quantachrome Autosorb iQ-MP-C-XR. To measure the surface area and average pore size of RHA and $\mathrm{ASiO}_{2}$, the BET equation was used ${ }^{28,29}$.

Fourier transform infrared spectroscopy (FTIR). The FTIR spectra were acquired by employing a Nicolet 6700 FT-IR (Thermo Electron Corporation). Potassium bromide was utilized to prepare a sample pellet, and the spectra were achieved in the range of $4000-400 \mathrm{~cm}^{-1}$ with a resolution of $4 \mathrm{~cm}^{-1}$ by the assemblage of $32 \mathrm{scans}$.

$X$-ray diffraction (XRD) and Thermal gravimetric analysis (TGA). In order to get the XRD pattern of RHA and $\mathrm{ASiO}_{2}$ adsorbent were acquired by the Rigaku Miniflex II desktop X-ray diffractometer (tube output voltage $30 \mathrm{kV}$ ) at a scan rate of $2.5^{\circ} \mathrm{min}^{-1}$ from 3 to $100^{\circ}$.

Thermal stability was investigated using SDT-Q 600 TGA Instrument (New Castle, DE) with a flow rate of nitrogen at $75 \mathrm{ml} / \mathrm{min}$ and the maximum temperature of $1000{ }^{\circ} \mathrm{C}$ with a heating rate of $10 \circ \mathrm{C} / \mathrm{min}$.

Gas adsorption. The $\mathrm{CO}_{2}, \mathrm{H}_{2}, \mathrm{CH}_{4}$, and $\mathrm{N}_{2}$ gases were adsorbed by $\mathrm{RHA}$ and $\mathrm{ASiO}_{2}$ using Quantachrome Autosorb iQ-MP-C-XR. The experimental procedure of adsorption is as follows: initially, about 30-100 mg of each sample was loaded for evacuation to remove all moisture and gases up to $200{ }^{\circ} \mathrm{C}$ under an $\mathrm{N}_{2}$ and $\mathrm{He}$ atmosphere for $3.5 \mathrm{~h}$. Then, the sample was loaded for adsorption of the gases at different temperatures under high-pressure. At the end of the adsorption studies, the system was switched to very low pressure for desorption 

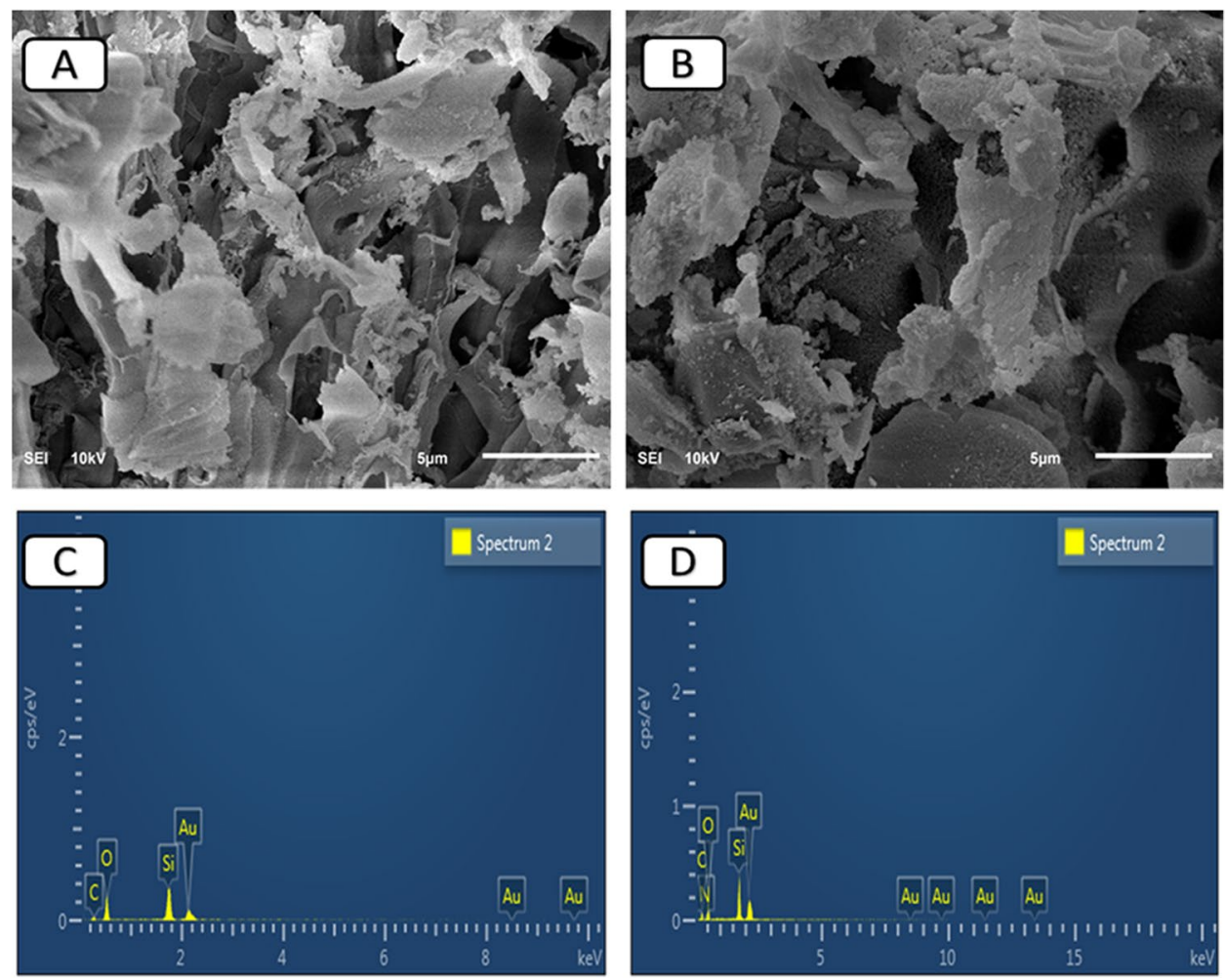

Figure 1. SEM micrographs and EDX analysis of RHA $(\mathbf{A}, \mathbf{C})$ and $\mathrm{ASiO}_{2}(\mathbf{B}, \mathbf{D})$.

of adsorbed gas. At this stage, one adsorption-desorption circle was performed. To investigate the reversibility of the adsorbent, three adsorption-desorption cycles were conducted ${ }^{4}$.

Computational methods. Geometry optimization and vibrational frequency calculations were carried out on simplified lowest energy isomer of silica cluster, $\mathrm{Si}_{4} \mathrm{O}_{6}{ }^{30}$, APTES and APTES functionalized silica using density functional theory (DFT) approach, with the exchange-correlation treated using the hybrid GGA exchange functional of Becke ${ }^{31}$ and the PW91 correlation functional of Perdew and Wang ${ }^{32}$, BPW91 and 6-31G basis set. Full structural optimizations were carried out to the minima, and vibrational frequency analysis showed the absence of imaginary frequencies. Total energies of the natural bonding orbitals of the adsorbents, bond properties, and their relative binding distances with the gases were computed. Variations in temperature adsorption studies were carried out using temperature command in the input files before running the calculations. Adsorption energies $\left(\Delta E_{\mathrm{ads}}\right)$ of the gases on the adsorbents were estimated using the eqs:

$$
\begin{gathered}
\Delta E_{a d s}=-\Delta E_{b i n d i n g} \\
\Delta E_{b i n d i n g}=E_{a d s / g a s}-\left(E_{a d s}+E_{g a s}\right)
\end{gathered}
$$

where $E_{\text {ads/gas }}$ represents the free energy of the adsorbent-gases complex and $E_{\mathrm{ads}}, E_{\mathrm{gas}}$ the free energies of the isolated adsorbents and the gases, respectively. All calculations were carried out using the Gaussian 09 program.

\section{Results and discussion}

Surface morphology. The SEM-EDX monographs of RHA and $\mathrm{ASiO}_{2}$ are shown in Fig. 1. There is no significant difference in the morphology of the surface before (Fig. 1A) and after the functionalization of RHA with APTES (Fig. 1B). The surface of $\mathrm{ASiO}_{2}$ became darker due to the presence of the amine group on the surface ${ }^{19}$. The EDX analysis of RHA (Fig. 1C) shows a significant amount of oxygen and silicon of $43.2 \%$ and $37.2 \%$, respectively. On the other hand, the functionalization of RHA with APTES was confirmed by EDX analysis (Fig. 1D) and showed a content of C, O, Si, and $\mathrm{N}$ of $27.4 \%, 38.3 \%, 31.1 \%$, and $3.2 \%$; respectively.

The XPS full scan of $\mathrm{ASiO}_{2}$ (Fig. 2A) demonstrates the prominent elemental variation in the structure, which confirms the treatment of RHA with APTES. This data showed the introduction of nitrogen and carbon into the structure and is compatible with the EDX data. The high-resolution carbon spectra (Fig. 2C) showed the peak at $\sim 284 \mathrm{eV}$ and $\sim 285 \mathrm{eV}$ that can be allocated to $\mathrm{C}-\mathrm{C}$ and $\mathrm{C}-\mathrm{N}$ or $\mathrm{C}-\mathrm{O}$ bond, respectively ${ }^{33}$. In the case of $\mathrm{N}$ (1s) spectra (Fig. 2D), the peak at $\sim 398 \mathrm{eV}$ corresponds to $\mathrm{NH}_{2}$ while the peak at $\sim 399 \mathrm{eV}$ corresponds to $\mathrm{NH}_{3}{ }^{+34}$. Figure $2 \mathrm{~B}$ showed the high-resolution scan of $\mathrm{O}(1 \mathrm{~s})$ with major peak and binding energy at $\sim 532.5$, which is related to ethoxy group bond $\mathrm{O}-\mathrm{C}^{33}$. The data in (Fig. 2E) demonstrates the high-resolution XPS band of $\mathrm{Si}(2 \mathrm{p})$. 

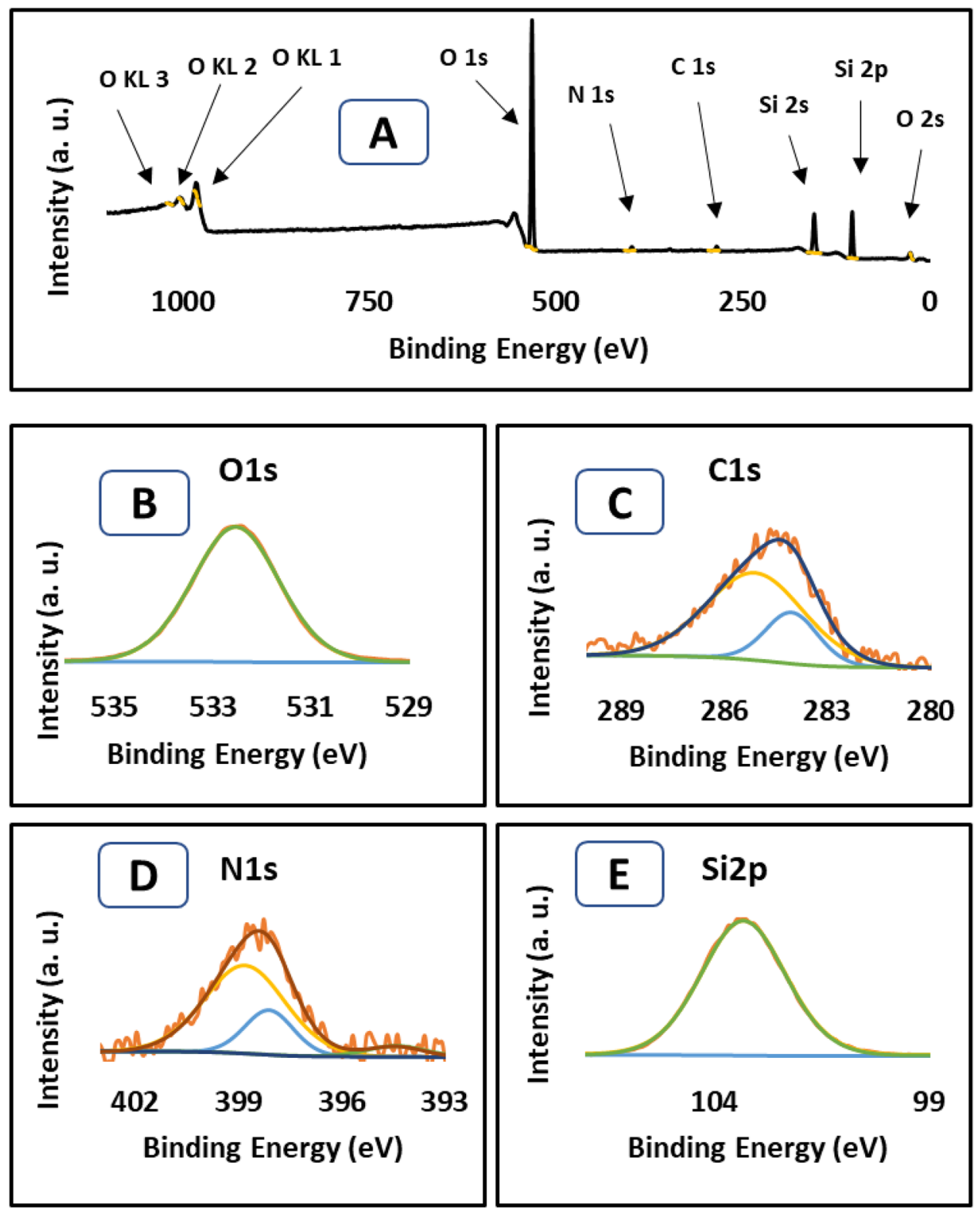

Figure 2. XPS analysis of $\mathrm{ASiO}_{2},(\mathbf{A})$ broad scan spectrum, the high-resolution spectrum of (B) O 1s, (C) C 1s, (D) N 1s, and (E) Si 2p.

The deconvoluted binding energy peaks at $\sim 103.3 \mathrm{eV}$ can be ascribed to the $\mathrm{Si}-\mathrm{O}$ bond ${ }^{35}$. For a comparative purpose, XPS data for $\mathrm{SiO}_{2}$ is provided in the supplementary Fig. 1S.

Pore size distribution measurements. Nitrogen adsorption was utilized to measure the surface area and demonstrate the pore features of the produced materials. Figure 3 shows the $\mathrm{N}_{2}$ adsorption isotherm of RHA and $\mathrm{ASiO}_{2}$ at $77 \mathrm{~K}$. The adsorbed volume of nitrogen on RHA uninterruptedly upsurged but did not attain a plateau close to the relative pressure $\left(\mathrm{P} / \mathrm{P}_{\mathrm{o}}\right)$ of 1.0 , inferring the existence of mesopores. In the case of $\mathrm{ASiO}_{2}$, the adsorption capability is lower at low pressure as compared to RHA confirming the loading of the amino group on the surface. The surface area, pore diameter, and pore volume of RHA and $\mathrm{ASiO}_{2}$ are shown in Table 1 .

The pore size distribution of RHA is from $3.3 \mathrm{~nm}$ to $12 \mathrm{~nm}$ with a pore volume of $0.25 \mathrm{~cm}^{3} / \mathrm{g}$, confirming the presence of mesopores in RHA (Fig. 3). However, the porous structure of $\mathrm{ASiO}_{2}$ (Fig. 3) mainly had mesopores distributed up to $12 \mathrm{~nm}$ with a mean diameter of $3.0 \mathrm{~nm}$ and a pore volume of $0.18 \mathrm{~cm}^{3} / \mathrm{g}$. The decrease in pore size and pore volume of $\mathrm{ASiO}_{2}$ is mainly due to pore filling with APTES ${ }^{19}$.

Thermal gravimetric analysis. The thermal stability of the silica-based materials was investigated with TGA analysis (Fig. 4). When the temperature reached $1000{ }^{\circ} \mathrm{C}, 5 \%$ of $\mathrm{RHA}$ and $85 \%$ of the $\mathrm{ASiO}_{2}$ materials remained as a residual solid. The analysis revealed that there are three zones in the TGA curves of each adsorbent. 

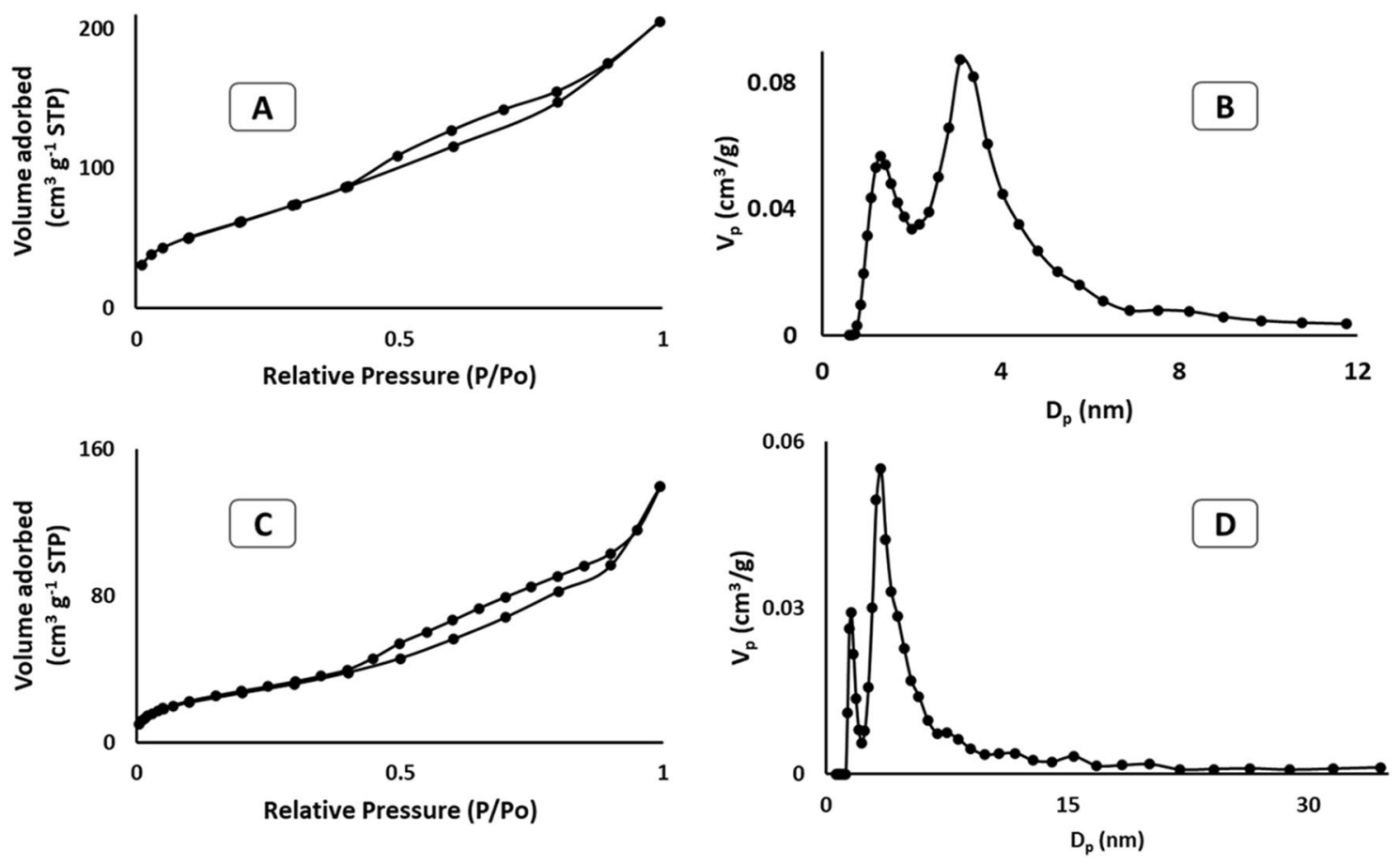

Figure 3. Nitrogen adsorption isotherm (A) and Pore size distribution (B) of RHA and $\mathrm{N}_{2}$ isotherm (C) and Pore size distribution (D) of $\mathrm{ASiO}_{2}$.

\begin{tabular}{|l|l|l|l|}
\hline Sample & $\mathbf{S}_{\text {BET }}\left(\mathbf{m}^{2} / \mathbf{g}\right)$ & $\mathbf{V}_{\mathbf{p}}\left(\mathbf{c m}^{3} / \mathbf{g}\right)$ & $\mathbf{D}_{\mathbf{p}}(\mathbf{n m})$ \\
\hline $\mathrm{RHA}$ & 220 & 0.248 & 3.385 \\
\hline $\mathrm{ASiO}_{2}$ & 100 & 0.179 & 3.099 \\
\hline
\end{tabular}

Table 1. Structural properties of $\mathrm{RHA}$ and $\mathrm{ASiO}_{2}$.

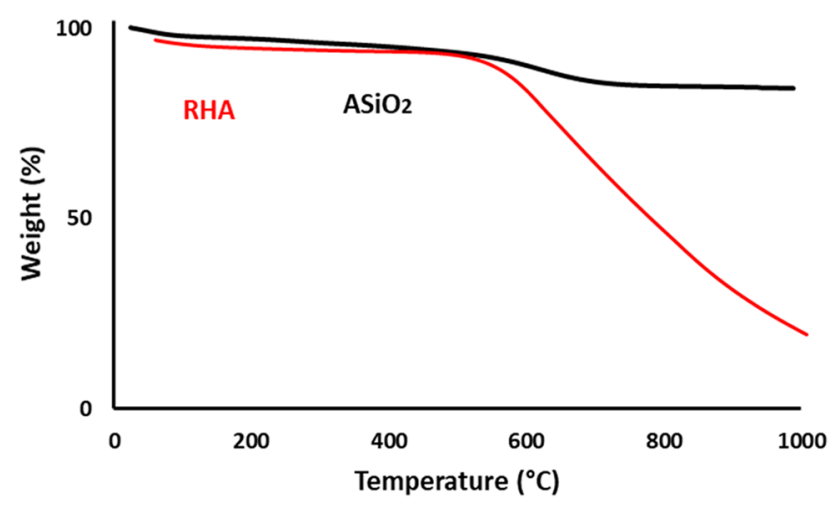

Figure 4. TGA analysis of $\mathrm{RHA}$ and $\mathrm{ASiO}_{2}$.

In the case of amine-modified silica, the adsorbent shows a little decrease of weight in the range of $50-600{ }^{\circ} \mathrm{C}$ due to the removal of guest molecules and moisture. Further, an increase in temperature up to $\sim 800{ }^{\circ} \mathrm{C}$ showed a small change in the weight of $\mathrm{ASiO}_{2}$ that is referred to as the degradation of the amine functional groups. Above $800^{\circ} \mathrm{C}$, no significant weight loss was observed, which is consistent with the findings of other researchers ${ }^{2}$. While in the case of RHA, the first weight loss up to $400^{\circ} \mathrm{C}$ was due to the release of moisture and other adsorbed gases. The second region with a significant decrease in weight extended up to $1000{ }^{\circ} \mathrm{C}$, which is related to the decomposition and co-condensation of silica components ${ }^{1}$. 


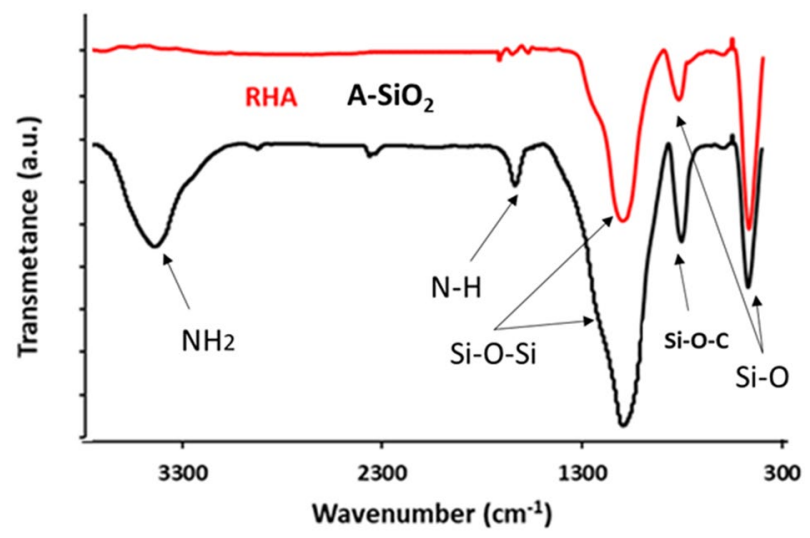

Figure 5. FTIR analysis of RHA and ASiO2.

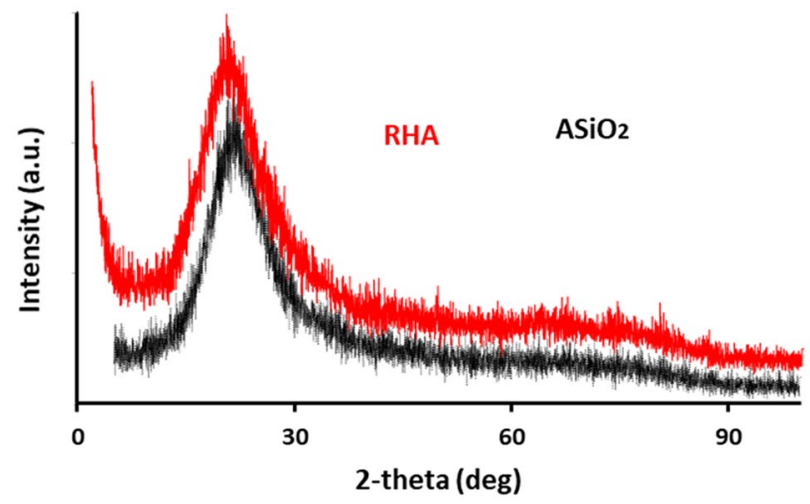

Figure 6. XRD patterns of $\mathrm{RHA}$ and $\mathrm{ASiO}_{2}$.

Spectroscopic characterizations. FTIR spectra of the silica-based materials are presented in Fig. 5, and the characteristic absorption bands can be observed for $\mathrm{RHA}$ and $\mathrm{ASiO}_{2}$. The absorption bands of RHA at $466 \mathrm{~cm}^{-1}$ is ascribed to $\mathrm{Si}-\mathrm{O}$ distortion, $800 \mathrm{~cm}^{-1}$ corresponds to $\mathrm{Si}-\mathrm{O}$ bending, and $\mathrm{Si}-\mathrm{O}-\mathrm{Si}$ stretching appeared at $1078 \mathrm{~cm}^{23}$. After modification of RHA with APTES, the peak at $790 \mathrm{~cm}^{-1}$ represent $\mathrm{Si}-\mathrm{O}-\mathrm{C}$ stretching vibration, while an additional peak appeared at $3420 \mathrm{~cm}^{-1}$ which corresponds to the silanol hydroxyl group $(\mathrm{Si}-\mathrm{OH})$. The peak at 3360 and $3240 \mathrm{~cm}^{-1}$ are represents the $-\mathrm{NH}_{2}$ vibrational stretching. The peak at $2920 \mathrm{~cm}^{-1}$ represents the $\mathrm{C}-\mathrm{H}$ stretching of $-\mathrm{CH}_{2}$ while the peak at $1630 \mathrm{~cm}^{-1}$ corresponds to the $\mathrm{N}-\mathrm{H}$ bending of the amine functional group ${ }^{1,19,36,37}$.

Figure 6 displays X-ray diffraction (XRD) patterns of $\mathrm{RHA}$ and $\mathrm{ASiO}_{2}$. A broad peak appeared at around $2 \theta=25^{\circ}$, which represents the semi-amorphous nature of the prepared materials. The XRD analysis showed that the structural properties of the prepared $\mathrm{ASiO}_{2}$ were maintained after modification.

Gas adsorption behavior. The adsorption isotherms of $\mathrm{CO}_{2}, \mathrm{CH}_{4}, \mathrm{H}_{2}$, and $\mathrm{N}_{2}$ on $\mathrm{ASiO}_{2}$ at different temperatures are shown in Figs. 7, 8 and 9. As expected, the adsorption capacity increases with a decrease in temperature. Consistent results were obtained from DFT calculations, which shows an increase in the binding energy as the temperature decreases (Table 2). The results also revealed that $\mathrm{ASiO}_{2}$ has a low adsorption capacity of $\mathrm{CH}_{4}, \mathrm{H}_{2}$, and $\mathrm{N}_{2}$ while it has an excellent affinity to adsorb $\mathrm{CO}_{2}$. Based on the binding energy and bond distance between the adsorbent and adsorbate, the same behaviour was observed in the DFT calculations (Table 2) which revealed a higher affinity of $\mathrm{ASiO}_{2}$ to adsorb $\mathrm{CO}_{2}$ than $\mathrm{CH}_{4}, \mathrm{H}_{2}$ or $\mathrm{N}_{2}$.

The adsorption mechanism of $\mathrm{CO}_{2}$ by $\mathrm{ASiO}_{2}$ can be explained through the formation of ammonium carbonate according to the following equation ${ }^{21}$ :

$$
\begin{gathered}
\mathrm{CO}_{2}+2 \mathrm{RNH}_{2} \rightarrow \mathrm{RNHCOO}^{-}+\mathrm{RNH}_{3}^{+} \\
\mathrm{CO}_{2}+2 \mathrm{R}_{2} \mathrm{NH} \rightarrow \mathrm{R}_{2} \mathrm{NCOO}^{-}+\mathrm{R}_{2} \mathrm{NH}_{2}^{+} \\
\mathrm{CO}_{2}+\mathrm{R}_{2} \mathrm{NH}+\mathrm{R}^{\prime} \mathrm{NH}_{2} \rightarrow \mathrm{R}_{2} \mathrm{NCOO}^{-}+\mathrm{R}^{\prime} \mathrm{NH}_{3}^{+}
\end{gathered}
$$




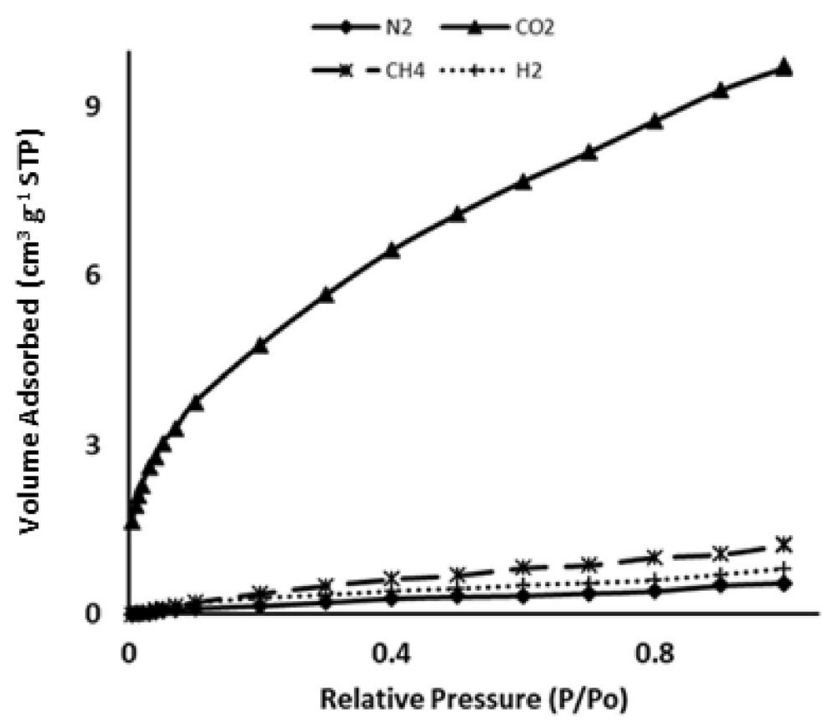

Figure 7. Adsorption isotherm of $\mathrm{ASiO}_{2}$ of different gases at $298 \mathrm{~K}$.

\begin{tabular}{|c|c|c|c|c|c|c|}
\hline \multirow[b]{2}{*}{ Temperature } & \multicolumn{3}{|l|}{ Silica } & \multicolumn{3}{|c|}{ Silica-APTES } \\
\hline & Gases & $\Delta \mathrm{E}_{\mathrm{ads}}(\mathrm{kcal} / \mathrm{mol})$ & Binding distance $(\AA)$ & Gases & $\Delta \mathrm{E}_{\text {ads }}(\mathrm{kcal} / \mathbf{m o l})$ & Binding distance $(\AA)$ \\
\hline \multirow{4}{*}{$298 \mathrm{~K}$} & $\mathrm{CO}_{2}$ & -8.65 & 2.891 & $\mathrm{CO}_{2}$ & -17.6 & 1.609 \\
\hline & $\mathrm{CH}_{4}$ & -7.00 & 3.233 & $\mathrm{CH}_{4}$ & -14.5 & 2.365 \\
\hline & $\mathrm{H}_{2}$ & -3.80 & 4.115 & $\mathrm{H}_{2}$ & -12.0 & 2.411 \\
\hline & $\mathrm{N}_{2}$ & -6.34 & 3.746 & $\mathrm{~N}_{2}$ & -9.2 & 3.176 \\
\hline \multirow{4}{*}{$273 \mathrm{~K}$} & $\mathrm{CO}_{2}$ & -11.7 & 2.891 & $\mathrm{CO}_{2}$ & -29.5 & 1.505 \\
\hline & $\mathrm{CH}_{4}$ & -10.2 & 2.233 & $\mathrm{CH}_{4}$ & -20.0 & 2.032 \\
\hline & $\mathrm{H}_{2}$ & -5.04 & 4.092 & $\mathrm{H}_{2}$ & -15.6 & 2.241 \\
\hline & $\mathrm{N}_{2}$ & -9.47 & 3.705 & $\mathrm{~N}_{2}$ & -14.0 & $2 . .982$ \\
\hline $77 \mathrm{~K}$ & $\mathrm{H}_{2}$ & -25.9 & 3.562 & $\mathrm{H}_{2}$ & -63.2 & 2.056 \\
\hline
\end{tabular}

Table 2. Adsorption energies and binding distances of $\mathrm{CO}_{2}, \mathrm{CH}_{4}, \mathrm{H}_{2}$ and $\mathrm{N}_{2}$ on silica and silica-APTES.

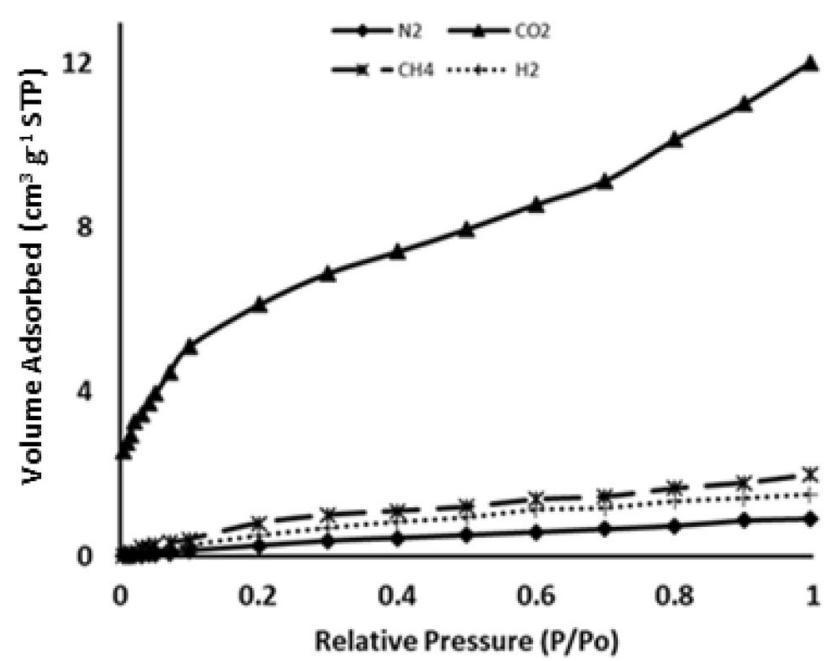

Figure 8. Adsorption isotherm of $\mathrm{ASiO}_{2}$ of different gases at $273 \mathrm{~K}$. 


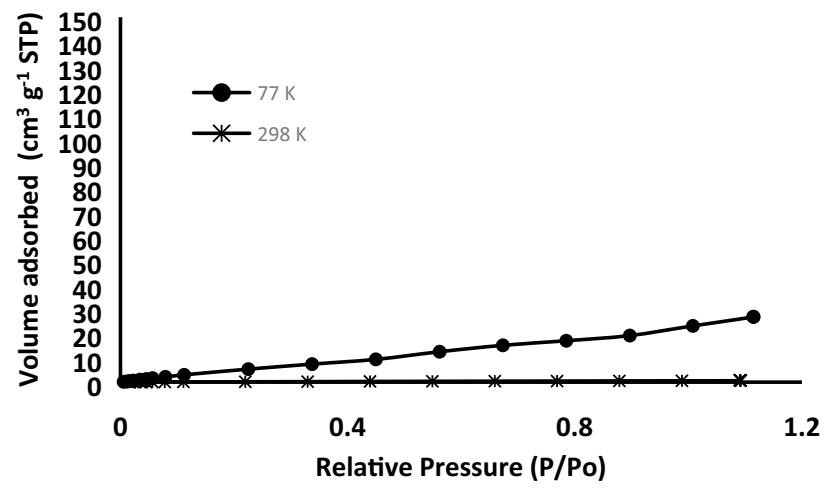

Figure 9. Adsorption isotherm of hydrogen on $\mathrm{ASiO}_{2}$ at $298 \mathrm{~K}$ and $77 \mathrm{~K}$.

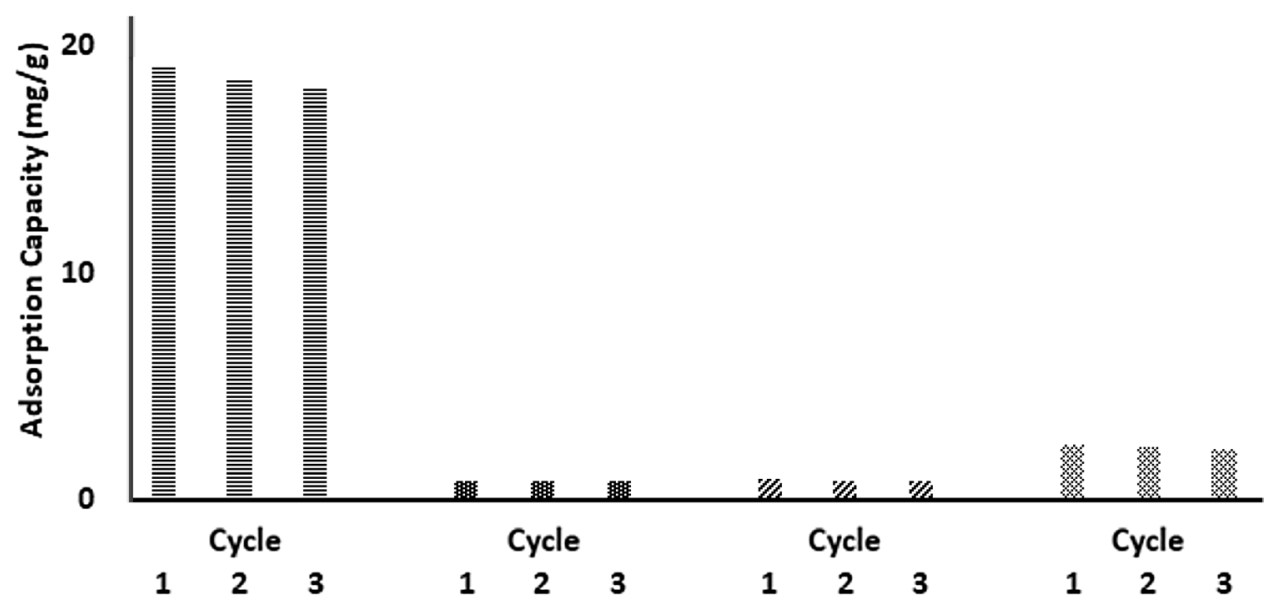

Figure 10. Adsorption recycle of $\mathrm{CO}_{2}, \mathrm{~N}_{2}, \mathrm{CH}_{4}$ at $298 \mathrm{~K}$, and $\mathrm{H}_{2}$ at $77 \mathrm{~K}$ on $\mathrm{ASiO}_{2}$.

The adsorption capacity of RHA for $\mathrm{CO}_{2}$ was $0.33 \mathrm{mmol} / \mathrm{g}$ while that of $\mathrm{ASiO}_{2}$ was $0.43 \mathrm{mmol} / \mathrm{g}$. This improvement in the adsorption capacity due to the amine functional group attached to the silica, as shown in the previous equation. These results are in good agreement with the DFT result that shows a decrease in the energy bandgap between HOMO/LUMO after the functionalization of RHA with the amine group (Fig. 11).

Figure 7 exhibits an excellent gas separation behaviour of $\mathrm{ASiO}_{2}$ in which a $\mathrm{CO}_{2} / \mathrm{CH}_{4}$ separation factor (amount adsorbed of $\mathrm{CO}_{2}$ /amount adsorbed of $\mathrm{CH}_{4}$ ) of 8.6 was achieved, while the separation factors of $\mathrm{CO}_{2} /$ $\mathrm{N}_{2}$ and $\mathrm{CO}_{2} / \mathrm{H}_{2}$ gases were 21.6 and 12.3 ; respectively ${ }^{38}$.

At $273 \mathrm{~K}$, the adsorption isotherms (Fig. 8) showed the same general behaviour of adsorption affinity with a slight decrease in the separation factors. The separation factors of $\mathrm{CO}_{2} / \mathrm{CH}_{4}, \mathrm{CO}_{2} / \mathrm{N}_{2}$, and $\mathrm{CO}_{2} / \mathrm{H}_{2}$ were $6,13.5$, and 7.7 , respectively.

Figure 9 showed a good affinity of $\mathrm{ASiO}_{2}$ to adsorb $\mathrm{H} 2$ at $77 \mathrm{~K}$ with an adsorption capacity of $1.2 \mathrm{mmol} / \mathrm{g}$, whereas at $298 \mathrm{~K}$, the adsorption capacity was $0.04 \mathrm{mmol} / \mathrm{g}$. The high binding energy of $-63.2 \mathrm{kcal} / \mathrm{mol}$ (Table 2) suggests that this behaviour can be related to the formation of hydrogen bonds between hydrogen and silicon at $77 \mathrm{~K}$.

The reversibility of gas adsorption was investigated by back-to-back adsorption/desorption cycles, as shown in Fig. 10. The results showed around $5 \%$ reduction in the adsorption capacity of $\mathrm{CO}_{2}$ between the 1 st and $3 \mathrm{rd}$ cycles. Besides, the decrease in $\mathrm{CH}_{4}, \mathrm{~N}_{2}$, and $\mathrm{H}_{2}$ adsorption capacities after the 3rd cycle was about $10 \%, 6 \%$, and $8 \%$, respectively. This indicates that a simple reduction of the pressure cannot recover a small fraction of the adsorbed molecules; it might also need an elevated temperature to desorb. We believe that if the adsorption/ desorption cycles were repeated many more times, the rate of decrease in adsorption capacity would diminish, and the amount adsorbed will be desorbed entirely.

Table 3 shows a collection of data reported on gas adsorption on silica-based materials. Comparable results were noticed for the adsorption capacity of $\mathrm{CO}_{2}$ and $\mathrm{H}_{2}$. However, higher values were also noticed due to differences in operating temperature or the specific surface area.

Computational results of gas adsorption. Figure 11 shows the optimized molecular structures of silica, $\mathrm{Si}_{4} \mathrm{O}_{6}$, APTES-functionalized silica, and their frontier orbital distribution. As predicted from the molecular orbital theory, the effectiveness of interaction between two reacting molecules is dependent on their frontier 


\begin{tabular}{|c|c|c|c|c|c|c|c|c|}
\hline Sample & \begin{tabular}{|l|}
$\mathrm{CO}_{2}$ \\
$(\mathrm{mmol} / \mathrm{g})$
\end{tabular} & \begin{tabular}{|l|}
$\mathrm{CH}_{4}$ \\
$(\mathrm{mmol} / \mathrm{g})$
\end{tabular} & $\mathrm{H}_{2}(\mathrm{mmol} / \mathrm{g})$ & $\mathrm{N}_{2}(\mathrm{mmol} / \mathrm{g})$ & Temp. (K) & \begin{tabular}{|l|}
$\begin{array}{l}\text { Pressure } \\
\text { (atm.) }\end{array}$ \\
\end{tabular} & $\mathrm{S}_{\mathrm{BET}}\left(\mathrm{m}^{2} / \mathrm{g}\right)$ & References \\
\hline${ }^{*} \mathrm{ASiO}_{2}$ & 0.43 & 0.05 & 0.035 & 0.03 & 298 & 1 & 223 & Present \\
\hline${ }^{*} \mathrm{ASiO}_{2}$ & 0.54 & 0.09 & \begin{tabular}{|l|}
0.07 \\
\end{tabular} & 0.04 & 273 & 1 & 223 & Present \\
\hline${ }^{*} \mathrm{ASiO}_{2}$ & & & 1.2 & & 77 & 1 & 223 & Present \\
\hline \begin{tabular}{|l|} 
APTS- \\
MCM-41
\end{tabular} & 0.54 & & & & 303 & 1 & 198 & 15 \\
\hline SG-APTS & 0.9 & & & & 275 & 10 & 270 & 19 \\
\hline $\begin{array}{l}\text { MCM-48/ } \\
\text { TREN }\end{array}$ & 1.5 & & & & - & - & 263 & 20 \\
\hline MS-400 (25) & 3.9 & & & & 348 & 1 & 33 & 22 \\
\hline SBA-PEI & 0.8 & & & & 298 & 1 & 5 & 21 \\
\hline SBA-AP & 0.85 & & & & 293 & 1 & 562 & 18 \\
\hline APTES-SiO ${ }_{2}$ & 2.3 & & & & 273 & 1 & 654 & 2 \\
\hline MCM-41 & & & $1.2-2.4$ & & 77 & 1 & 916-1060 & 24 \\
\hline MCF & & & 1.1 & & 77 & 1 & 600 & 25 \\
\hline Pt-MCF & & & $1.5-2.5$ & & & & $570-588$ & \\
\hline Al-MCF & & & $0.5-1.5$ & & & & $322-498$ & \\
\hline $\mathrm{SiO}_{2}$ & & & 3 & & 77 & 1 & 4810 & 26 \\
\hline $\mathrm{SiO}_{2}-\mathrm{OTiCl}_{3}$ & & & $1-2$ & & & & $3350-4790$ & \\
\hline SBA-15 & & & $6-30$ & & 77 & 1 & $702-3274$ & 23 \\
\hline RHA & & & 0.15 & & 77 & 1 & 14.05 & 43 \\
\hline
\end{tabular}

Table 3. Gas adsorption on different silica-based adsorbents.

(a)
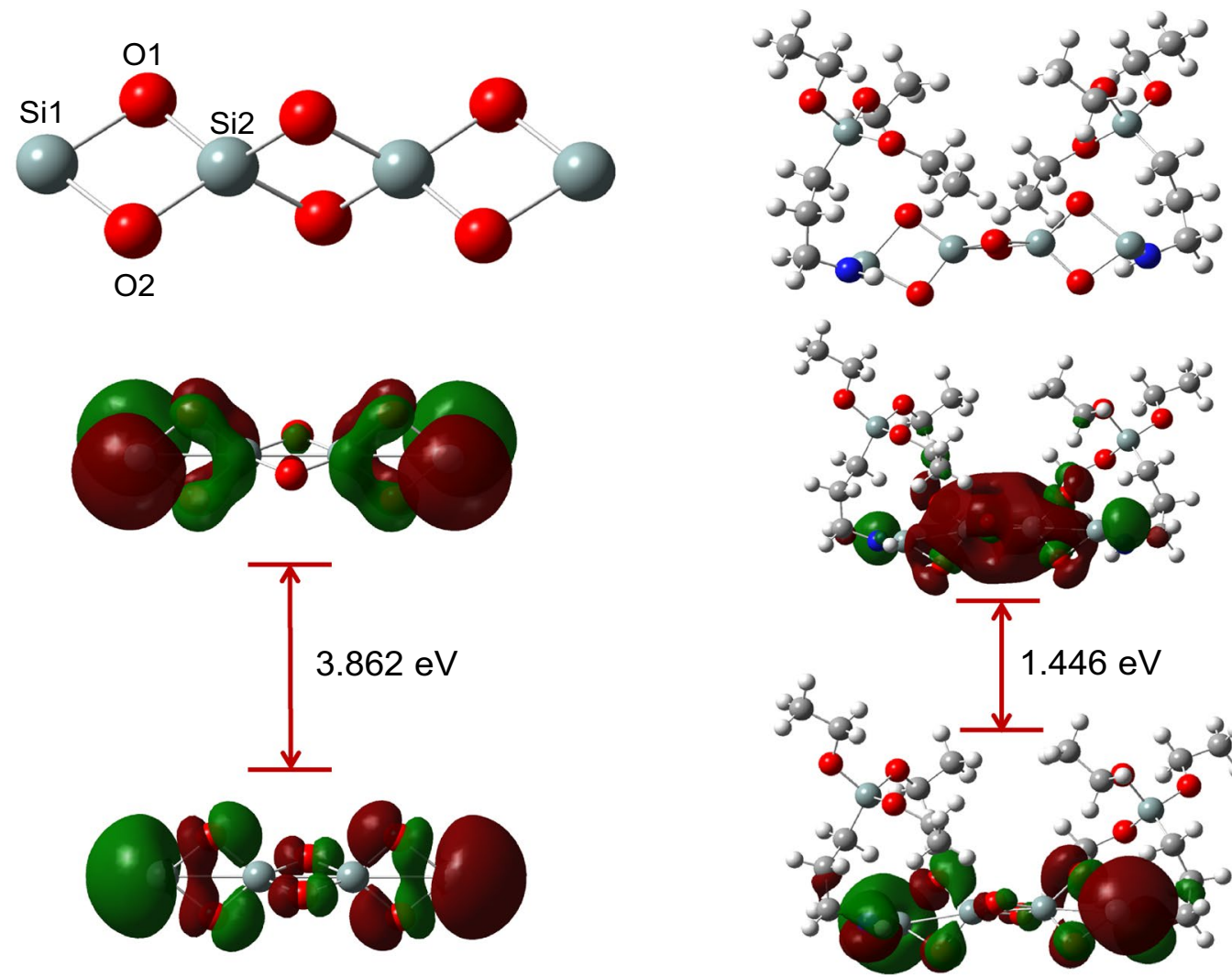

$$
\eta=1.934 \mathrm{eV}
$$

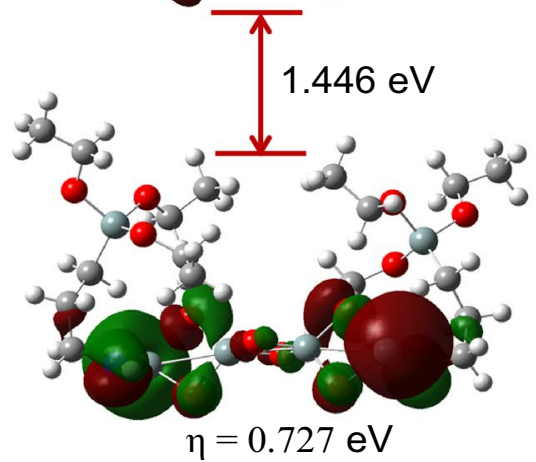

Figure 11. Optimized molecular structures (a) and frontier orbital distributions (b) of silica cluster, $\mathrm{Si}_{4} \mathrm{O}_{6}(\mathrm{left})$ and silica-APTES (right). 
$\mathrm{CO}_{2}$

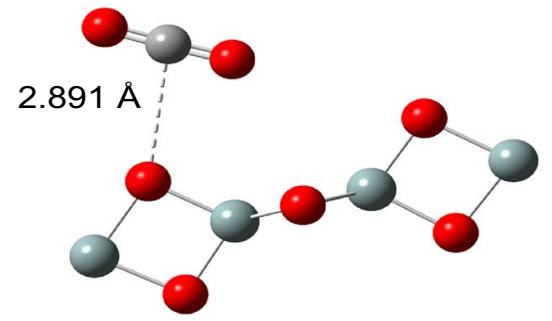

$\mathrm{CH}_{4}$

$\mathrm{H}_{2}$
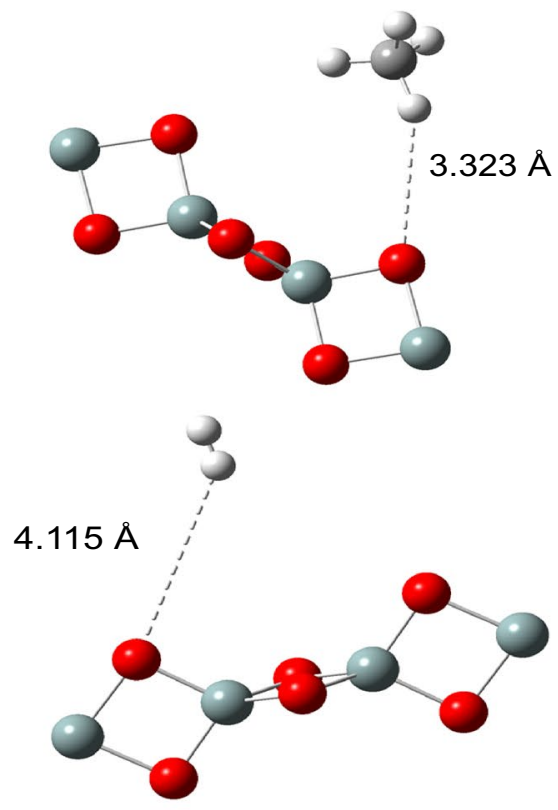

$\mathrm{N}_{2}$

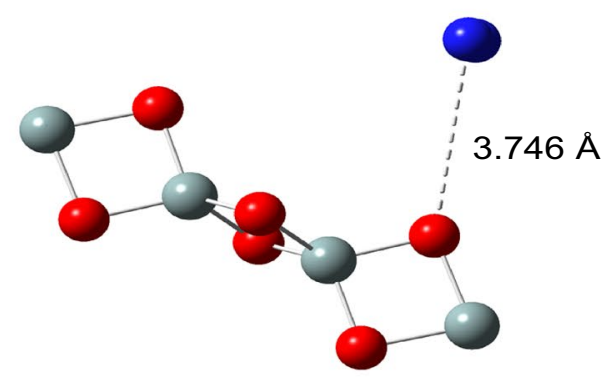

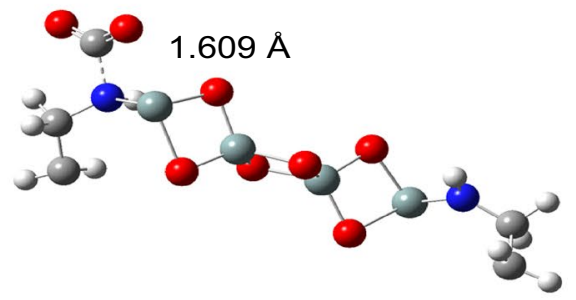
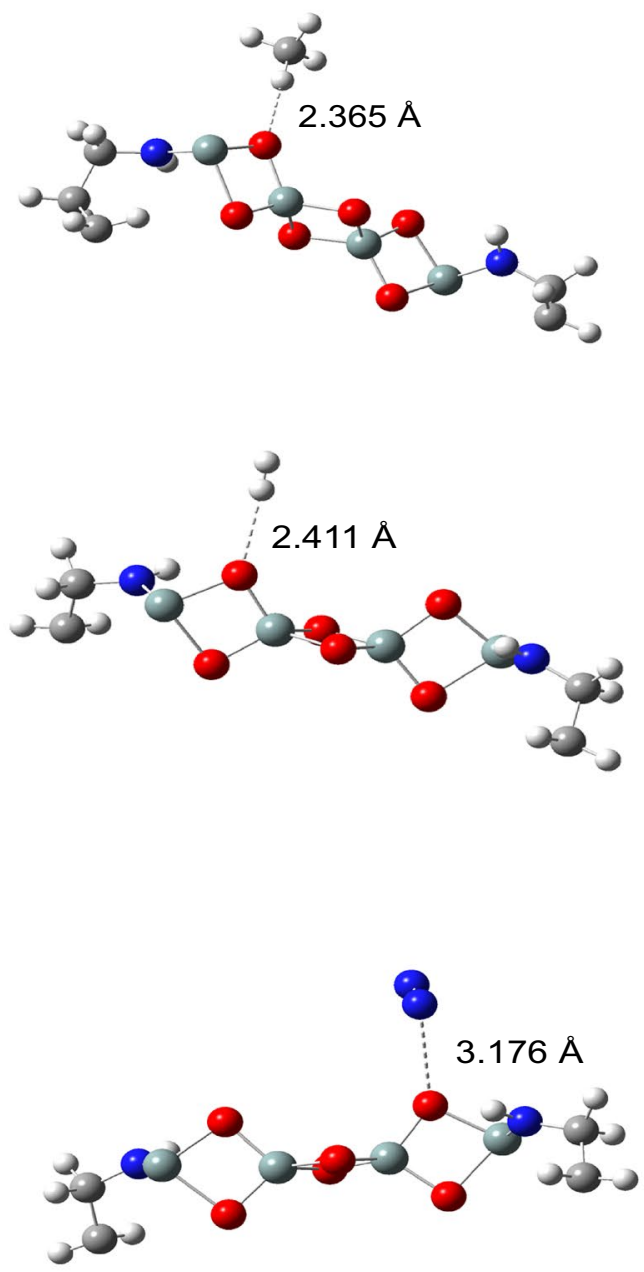

Figure 12. Optimized adsorption of $\mathrm{CO}_{2}, \mathrm{CH}_{4}, \mathrm{H}_{2}$ and $\mathrm{N}_{2}$ on silica, $\mathrm{Si}_{4} \mathrm{O}_{6}$ (left) and silica-APTES (right) at $298 \mathrm{~K}$.

orbitals (HOMO/LUMO) distribution, and the energy gap maintained within ${ }^{39}$. Molecules having lower energy gaps are predicted to exhibit high charge transfer characteristics and are therefore more reactive. Frontier orbital distribution analysis (Fig. 11b) showed that the HOMO-LUMO orbitals were fairly distributed across the silica fragment in both adsorbents. Furthermore, the functionalization of silica with APTES led to a significant decrease in the energy gap from $3.862 \mathrm{eV}$ to $1.446 \mathrm{eV}$, which consequently implies a substantial increase in reactivity towards the adsorbed gases. Besides, global hardness $(\eta)$ of the adsorbents, which expresses their tendency to donate their non-bonding electrons during interactions, revealed that the functionalization of silica led to a significant decrease in hardness and a consequent increase in charge transferability.

Moreover, interactions of the adsorbents with $\mathrm{CO}_{2}, \mathrm{CH}_{4}, \mathrm{H}_{2}$, and $\mathrm{N}_{2}$ gases were further simulated at $298 \mathrm{~K}$ and $273 \mathrm{~K}$, while interactions at $77 \mathrm{~K}$ were simulated for $\mathrm{H}_{2}$ gas alone. The optimized structures representing the lowest energy conformers of the adsorbed gases onto the adsorbents at $298 \mathrm{~K}$ are presented in Fig. 12. Besides, the binding distances between pristine silica and the gases at $298 \mathrm{~K} ; \mathrm{CO}_{2}(2.891 \AA), \mathrm{CH}_{4}(3.233 \AA), \mathrm{H}_{2}(4.115 \AA)$ and $\mathrm{N}_{2}(3.746 \AA)$ as opposed to $1.609 \AA, 2.365 \AA, 2.411 \AA$, and $3.176 \AA$ in APTES-functionalized silica (supplementary Tables 1-3S) further revealed that the gases only undergo weak physical adsorptions onto pristine silica due to weak van der Waals interactions between the silica surface and the gas molecules which resulted 
in low adsorption energies. Adsorptions of the gases on APTES-functionalized silica were more favorable with more negative adsorption energies and shorter binding distances due to the increase in surface interactions. Furthermore, functionalized silica showed more affinity to $\mathrm{CO}_{2}$ with adsorption energy, $\Delta E_{\text {ads }}$ of $-17.6 \mathrm{kcal} / \mathrm{mol}$ (at $298 \mathrm{~K})$, relative to $\mathrm{CH}_{4}(-14.5 \mathrm{kcal} / \mathrm{mol}), \mathrm{H}_{2}(-12.0 \mathrm{kcal} / \mathrm{mol})$ and $\mathrm{N}_{2}(-9.2 \mathrm{kcal} / \mathrm{mol})$ gases, and $-29.5 \mathrm{kcal} /$ $\mathrm{mol}($ at $273 \mathrm{~K})$, relative to $\mathrm{CH}_{4}(-20.0 \mathrm{kcal} / \mathrm{mol}), \mathrm{H}_{2}(-15.6 \mathrm{kcal} / \mathrm{mol})$ and $\mathrm{N}_{2}(-14.0 \mathrm{kcal} / \mathrm{mol})$ as found from experimental studies. The relatively stronger adsorption of $\mathrm{CO}_{2}$ onto APTES-functionalized silica resulting in binding distances $1.609 \AA(298 \mathrm{~K})$ and $1.505 \AA$ ( $273 \mathrm{~K})$ could be due to the enhancement in basicity character of the adsorbent upon functionalization which led to chemical interaction (chemisorption) with $\mathrm{CO}_{2}$ as implied by the binding distances ${ }^{40,41}$, and in accordance with the hard-soft acid-base (HSAB) principle ${ }^{42}$. Overall, DFT results are in good correlation with experimental data and showed that the functionalization of silica with APTES led to an increase in adsorption efficiency, and adsorption efficiency increases with a decrease in temperature.

\section{Conclusions}

The utilization of agricultural waste material (Rice Husk) was successfully achieved to prepare silica (RHA) which was functionalized with APTES to get aminated silica. Quantum chemical DFT calculations revealed that the functionalization of RHA to produce $\left(\mathrm{ASiO}_{2}\right)$ resulted in a decrease in the HOMO-LUMO energy gap, a corresponding reduction in hardness, an increase in charge transfer characteristics and consequently higher interactions with the studied gases. The adsorption capacity of the gases on $\mathrm{ASiO}_{2}$ increased in the order $\mathrm{CO}_{2}>\mathrm{CH}_{4}>\mathrm{H}_{2}>\mathrm{N}_{2}$, which was consistent with the DFT calculations in terms of adsorption energy and binding distance. Aminated silica showed a good separation factor of $\mathrm{CO}_{2}$ from the other studied gases at $298 \mathrm{~K}$. The separation factor of $\mathrm{CO}_{2} / \mathrm{N}_{2}$ and $\mathrm{CO}_{2} / \mathrm{CH}_{4}$ at $298 \mathrm{~K}$ was 21.5 and 8.6 , respectively. The separation factor of $\mathrm{ASiO}_{2}$ towards binary mixture of the gases makes it a suitable candidate for applications in natural gas separation as well as in environmental applications.

Received: 27 October 2019; Accepted: 27 October 2020

Published online: 11 November 2020

\section{References}

1. Suteewong, T. et al. Synthesis and formation mechanism of aminated mesoporous silica nanoparticles. Chem. Mater. 24, 3895-3905 (2012).

2. Cui, S. et al. Preparation of amine-modified SiO2 aerogel from rice husk ash for CO2 adsorption. J. Porous Mater. 24(2), 455-461 (2017).

3. Sun, Y. et al. Quantification of amine functional groups on silica nanoparticles: a multi-method approach. Nanoscale Adv. 1, 1598-1607 (2019).

4. Zhang, X. et al. Effects of hydrofluoric acid pre-deashing of rice husk on physicochemical properties and CO2 adsorption performance of nitrogen-enriched biochar. Energy 91(1), 903-910 (2015).

5. Yi, H. et al. Adsorption separation of CO2, CH4, and N2 on microwave activated carbon. Chem. Eng. J. 215-216(1), 635-642 (2013).

6. Horikawa, M. S., Rossi, F., Gimenes, M. L., Costa, C. M. M. \& da Silva, M. G. C. Chemical absorption of H2S for biogas purification. Braz. J. Chem. Eng. 21(3), 415-422 (2004).

7. Tuinier, M. J. \& van Sint Annaland, M. Biogas purification using cryogenic packed-bed technology. Ind. Eng. Chem. Res. 51(15), 5552-5558 (2012).

8. Yeo, Z. Y., Chew, T. L., Zhu, P. W., Mohamed, A. R. \& Chai, S.-P. Conventional processes and membrane technology for carbon dioxide removal from natural gas: a review. J. Nat. Gas Chem. 21(3), 282-298 (2012).

9. Aaron, D. \& Tsouris, C. Separation of CO2 from flue gas: a review. Sep. Sci. Technol. 40(1-3), 321-348 (2005).

10. Sun, N. et al. Surface-modified spherical activated carbon materials for pre-combustion carbon dioxide capture. $R S C A d v$. 5(42), 33681-33690 (2015).

11. Moon, S. H. \& Shim, J. W. A novel process for $\mathrm{CO} 2 / \mathrm{CH} 4$ gas separation on activated carbon fibers-electric swing adsorption. J. Colloid Interface Sci. 298(2), 523-528 (2006).

12. Khalili, S., Khoshandam, B. \& Jahanshahi, M. A comparative study of CO2and CH4adsorption using activated carbon prepared from pine cone by phosphoric acid activation. Korean J. Chem. Eng. 33(10), 2943-2952 (2016).

13. Álvarez-Gutiérrez, N., García, S., Gil, M. V., Rubiera, F. \& Pevida, C. Dynamic performance of biomass-based carbons for CO2/ $\mathrm{CH} 4$ separation. approximation to a pressure swing adsorption process for biogas upgrading. Energy Fuels 30(6), 5005-5015 (2016).

14. Caldwell, S. J. et al. Carbon dioxide separation from nitrogen/hydrogen mixtures over activated carbon beads: adsorption isotherms and breakthrough studies. Energy Fuels 29(6), 3796-3807 (2015).

15. Gao, F. et al. Dynamic properties in CO2adsorption on amine-modified MCM-41. J. Process Mech. Eng. 227(2), 106-116 (2012).

16. Alias, N. H., Kamaruddin, K. S. N. \& Bhatti, I. CO2 separation using modified MCM-41 in PSA system. Int. J. Chem. Environ. Eng. 1(2), 85-90 (2010).

17. Chew, T. L., Ahmad, A. L. \& Bhatia, S. Ordered mesoporous silica (OMS) as an adsorbent and membrane for separation of carbon dioxide (CO2). Adv. Colloid Interface Sci. 153, 43-57 (2010).

18. Zukal, A., Jagiello, J., Mayerová, J. \& Čejka, J. Thermodynamics of CO2 adsorption on functionalized SBA-15 silica. NLDFT analysis of surface energetic heterogeneity. Phys. Chem. Chem. Phys. 13(34), 15468-15475 (2011).

19. Sakpal, T., Kumar, A., Kamble, S. \& Kumar, R. Carbon dioxide capture using amine-functionalized silica gel. Indian J. Chem. 51, 1214-1222 (2012).

20. Bhagiyalakshmi, M., Yun, L. J., Anuradha, R. \& Jang, H. T. Utilization of rice husk ash as silica source for the synthesis of mesoporous silicas and their application to CO2 adsorption through TREN/TEPA grafting. J. Hazard. Mater. 175(1-3), 928-938 (2010).

21. Gargiulo, N., Peluso, A., Aprea, P., Pepe, F. \& Caputo, D. CO2 adsorption on polyethyleneimine-functionalized SBA-15 mesoporous silica: isotherms and modeling. J. Chem. Eng. Data 59, 896-902 (2014).

22. Zeng, W. \& Bai, H. Swelling-agent-free synthesis of rice husk derived silica materials with large mesopores for efficient CO2 capture. Chem. Eng. J. 251, 1-9 (2014).

23. Bera, B. \& Das, N. Synthesis of high surface area mesoporous silica SBA-15 for hydrogen storage application. Int. J. Appl. Ceram. Technol. 16, 294-303 (2019).

24. Sheppard, D. A. \& Buckley, C. E. Hydrogen adsorption on porous silica. Int. J. Hydrogen Energy 33, 1688-1692 (2008). 
25. Melaet, G., Stavila, V., Klebanoff, L. \& Somorjai, G. A. The effect of aluminum and platinum additives on hydrogen adsorption on mesoporous silicates. Phys. Chem. Chem. Phys. 20(17), 12075-12083 (2018).

26. Suraweera, N. S., Albert, A. A., Humble, J. R., Barnes, C. E. \& Keffer, D. J. Hydrogen adsorption and diffusion in amorphous, metal-decorated nanoporous silica. Int. J. Hydrogen Energy 39, 9241-9253 (2014).

27. Hou, X. et al. Preparation and application of guanidyl-functionalized graphene oxide-grafted silica for efficient extraction of acidic herbicides by Box-Behnken design. J. Chromatogr. A 1571, 65-75 (2018).

28. Ravikovitch, P. I., Haller, G. L. \& Neimark, A. V. Density functional theory model for calculating pore size distributions: pore structure of nanoporous catalysts. Adv. Colloid Interface Sci. 76-77, 203-226 (1998)

29. Lastoskie, C., Gubbins, K. E. \& Quirke, N. Pore size distribution analysis of microporous carbons: a density functional theory approach. J. Phys. Chem 97, 4786-4796 (1993).

30. Lu, W. C. et al. Structures and fragmentations of small silicon oxide clusters by ab initio calculations. J. Phys. Chem. A 107(36), 6936-6943 (2003).

31. Becke, A. D. Density-functional thermochemistry. III. The role of exact exchange. J. Chem. Phys. 98(7), 5648-5652 (1993).

32. Perdew, J. P. \& Wang, Y. Accurate and simple analytic representation of the electron-gas correlation energy. Phys. Rev. B 45(23), 13244-13249 (1992).

33. Knorr, D. B. et al. Use of 3-aminopropyltriethoxysilane deposited from aqueous solution for surface modification of III-V materials. Appl. Surf. Sci. 320, 414-428 (2014).

34. Lee, J. H. et al. Investigation of the mechanism of chromium removal in (3-aminopropyl)trimethoxysilane functionalized mesoporous silica. Sci. Rep. 8, 12078 (2018).

35. Li, M. et al. Realization of colored multicrystalline silicon solar cells with $\mathrm{SiO} 2 / \mathrm{SiNx}$ : $\mathrm{H}$ double layer antireflection coatings. Int. J. Photoenergy 2013, 1-8 (2013).

36. Peng, S. et al. Aminated mesoporous silica nanoparticles for the removal of low-concentration malodorous aldehyde gases. Environ. Sci. Nano 5, 2663-2671 (2018).

37. Aneja, K. S., Bohm, S., Khanna, A. S. \& Bohm, H. L. M. Graphene-based anticorrosive coatings for Cr $(<\mathrm{scp}>$ vi $</$ scp $>)$ replacement. Nanoscale 7, 17879-17888 (2015).

38. Kang, D.-Y. et al. Direct synthesis of single-walled aminoaluminosilicate nanotubes with enhanced molecular adsorption selectivity. Nat. Commun. 5(1), 3342 (2014).

39. Abdulazeez, I., Basheer, C. \& Al-Saadi, A. A. Selective colorimetric sensing of nickel(II) ions using 2-hydroxy-5-nitrobenzaldehyde4-hydroxy benzoyl hydrazone ligand: spectroscopic and DFT insights. J. Mol. Liq. 264, 58-65 (2018).

40. Olsen, R. A., Philipsen, P. H. T. \& Baerends, E. J. CO on Pt(111): a puzzle revisited. J. Chem. Phys. 119(8), 4522-4528 (2003).

41. Jiang, D. E. \& Carter, E. A. Adsorption and dissociation of CO on Fe(110) from first principles. Surf. Sci. 570(3), 167-177 (2004).

42. Parr, R. G. \& Chattaraj, P. K. Principle of maximum hardness. J. Am. Chem. Soc. 113(5), 1854-1855 (1991).

43. Panchariya, D. K., Rai, R. K., Kumar, E. A. \& Singh, S. K. Silica-rich MIL-101(Cr) for enhanced hydrogen uptake. J. Porous Mater. 26(4), 1137-1147 (2019).

\section{Acknowledgements}

The authors gratefully acknowledge the funding support of the Deanship of Scientific Research at King Fahd University of Petroleum and Minerals through a project Grant No. DF181034.

\section{Author contributions}

C.B. and I.H.A. proposed the concept of preparing materials and investigation for adsorption study and contributed to the discussions of research. R.B. and I.H.A. did the preparation, measurement, characterization, and analysis. I.A. performed the DFT analysis. R. B written the manuscript with the guidance of C.B. and I.H.A, and both of them supervised the research.

\section{Competing interests}

The authors declare no competing interests.

\section{Additional information}

Supplementary information is available for this paper at https://doi.org/10.1038/s41598-020-76460-0.

Correspondence and requests for materials should be addressed to I.H.A. or C.B.

Reprints and permissions information is available at www.nature.com/reprints.

Publisher's note Springer Nature remains neutral with regard to jurisdictional claims in published maps and institutional affiliations.

(c) Open Access This article is licensed under a Creative Commons Attribution 4.0 International License, which permits use, sharing, adaptation, distribution and reproduction in any medium or format, as long as you give appropriate credit to the original author(s) and the source, provide a link to the Creative Commons licence, and indicate if changes were made. The images or other third party material in this article are included in the article's Creative Commons licence, unless indicated otherwise in a credit line to the material. If material is not included in the article's Creative Commons licence and your intended use is not permitted by statutory regulation or exceeds the permitted use, you will need to obtain permission directly from the copyright holder. To view a copy of this licence, visit http://creativecommons.org/licenses/by/4.0/.

(c) The Author(s) 2020 